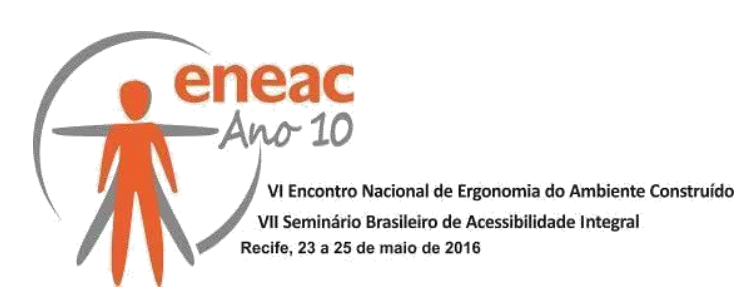

\title{
A CIDADE E SUAS CONEXÕES HUMANAS - ANÁLISE ESPACIAL E DIRETRIZES PARA INTERVENÇÃO URBANA EM CENTRO HISTÓRICO COMERCIAL - RECIFE/PE
}

\author{
NUNES, Mirella Lopes (1); \\ MOURA, Erika Fernanda da Silva (2); \\ MACIEL, Ana Maria Moreira (3) \\ Universidade Mauricio de Nassau, Arquiteta \\ e-mail: mirellaln@hotmail.com \\ ITEP, Mestre em Tecnologia Ambiental \\ e-mail: erikamoura.arquiteta@gmail.com \\ UFPE, Mestre em Gestão Pública \\ e-mail: anamariamaciel@yahoo.com.br
}

\begin{abstract}
RESUMO
Este trabalho busca a partir de análises históricas e físicas do Centro Histórico Comercial do Recife, propor diretrizes para requalificação urbana, a fim de resgatar o caminhar, a contemplação dos espaços, incentivar os encontros e, principalmente, trazer de volta ao espaço em estudo à vitalidade perdida com o passar dos anos. Foram pesquisados autores e publicações que abordassem os princípios de mobilidade urbana sustentável, espaços públicos contemporâneos e a dimensão humana das cidades. Utilizou-se também dados históricos da evolução urbana da área, seus aspectos legais, além de levantamentos físicos e fotográficos e entrevistas com os usuários para estruturar as diretrizes propostas.
\end{abstract}

Palavras-chave: requalificação urbana; centro histórico; recife.

\begin{abstract}
This paper seeks from historical and physical analysis of the Commercial Historic Centre of Recife, propose guidelines for urban renewal in order to rescue the walk, contemplation of spaces, encourage meetings and especially bring back into space under study at vitality lost over the years. They searched authors and publications that addressed the principles of sustainable urban mobility, contemporary public spaces and human dimension of the city, raised historical data of the urban development of the area and the legal aspects, as well as physical and photographic surveys and interviews with users.
\end{abstract}

Keywords: urban renovation; historical centre; recife.

\section{INTRODUÇÃO}

Este trabalho surge com o propósito de analisar os aspectos físico-espaciais do Bairro de São José e parte do Bairro de Santo Antônio, especificamente na área de comércio intenso e de grande memória afetiva e cultural para a cidade do Recife (figura 1). 


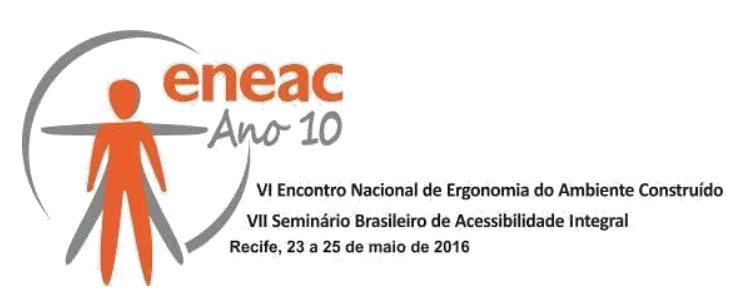

Figura 1. Bairro de Santo Antônio e parte do Bairro de São José. Mancha: área de estudo.

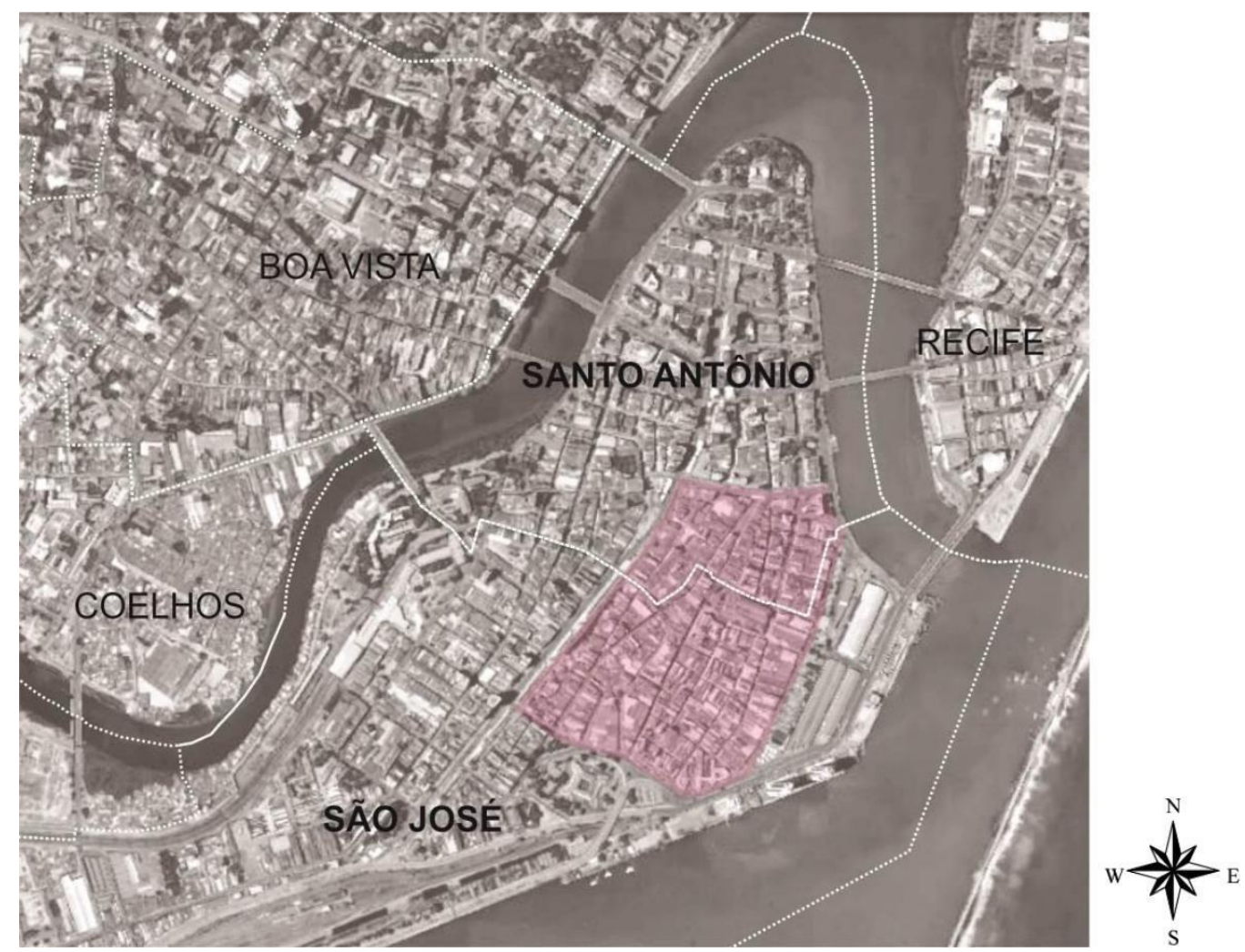

Fonte: Google Earth, editada por NUNES, 2015.

Nesses bairros encontram-se a maior concentração de edificações religiosas da cidade do Recife, além de outras edificações históricas como o Mercado de São José e o Forte das Cinco Pontas.

O centro comercial popular do Recife, que se encontra em sua maioria concentrado no bairro de São José, se caracteriza pela predominância do uso comercial e da grande concentração de edificações religiosas. Caracteriza-se também, pela expressiva presença de comércio ambulante, pela mobilidade urbana ineficaz e precária, seja para os pedestres, seja para os veículos motorizados ou não, pelas edificações abandonadas e descaracterizadas, entre outros.

Historicamente, o Bairro de São José em conjunto com os bairros do Recife e de Santo Antônio deram início à urbanização da cidade do Recife. Pela sua proximidade com Olinda, foi nessa área que tanto os portugueses quanto os holandeses se estabeleceram, fosse para morar, fosse como território de defesa. Em 1639, o bairro de São José se torna a "Nova Cidade Maurícia", pois antes disso os holandeses achavam impossível a ocupação nesta parte da llha de Antônio Vaz, que era vista como área de defesa devido à proximidade com o hoje Forte das Cinco Pontas (NEVES \& MENDONÇA JÚNIOR, 2007). Os holandeses permaneceram até 1654, quando houve a retomada das terras pelos portugueses.

Foi a partir de 1654, com as doações de terras às ordens e irmandades, que o bairro de São José começou a ser povoado por comerciantes vindos de Portugal. Assim se inicia o caráter comercial da área, até hoje bastante forte. De acordo com NEVES \& MENDONÇA JÚNIOR (2007), é nesse ano que os Capuchinhos recebem o sobrado de №. 298 e deram início a construção da Igreja de Nossa Senhora da Penha.

As edificações religiosas começaram a ser construídas pelos comerciantes, que demonstravam através delas o seu prestígio e importância para a sociedade. 


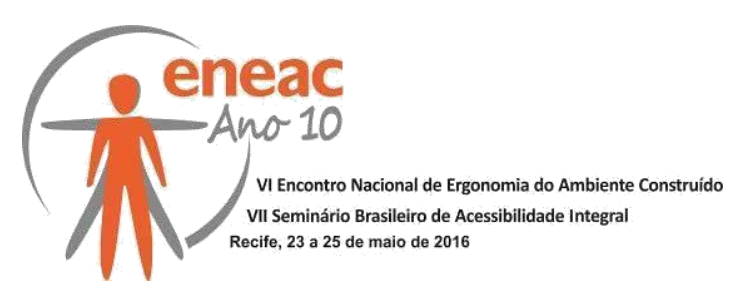

Despretensiosamente, esses comerciantes induziram o traçado urbano dessas terras. (NEVES \& MENDONÇA JÚNIOR, 2007).

No início do século $X X$, o centro da cidade, era constituído pelos bairros do Recife, Santo Antônio, São José e boa parte do bairro da Boa Vista, já havendo uma consolidação dos bairros periféricos. Com a evolução urbanística da cidade de Recife e do Bairro de São José, especificamente, nota-se o abandono da área original/primitiva.

Nesse trabalho, a partir de entrevistas com usuários e análises histórico-físicas da área, foram propostas diretrizes para requalificação urbana, com o objetivo de resgatar 0 caminhar, a contemplação dos espaços, incentivar os encontros e, principalmente, trazer de volta ao espaço em estudo à vitalidade perdida com o passar dos anos, devolvendo a população um espaço público de qualidade.

\section{A CIDADE E SUAS CONEXÕES HUMANAS}

Em bairros mais antigos de muitas cidades, é possível perceber nas edificações como a relação com a escala humana era valorizada, pois eram construídos para serem admirados de perto, por quem caminhava. As figuras 2 e 3 mostram como os pavimentos térreos eram tratados para promover a integração do edifício com a rua e com o cidadão, com usos diversos; e as ruas não priorizavam os automóveis em detrimento do pedestre.

Figura 2. Roma. Exemplo de cidade tradicional.

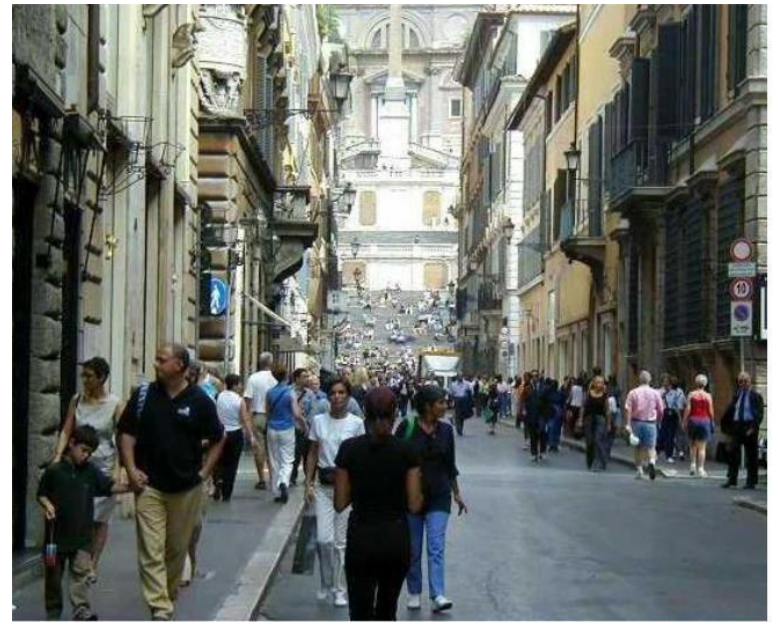

Fonte: Emanuelle Antonino, 2014.
Figura 3. Veneza. Exemplo de cidade tradicional.

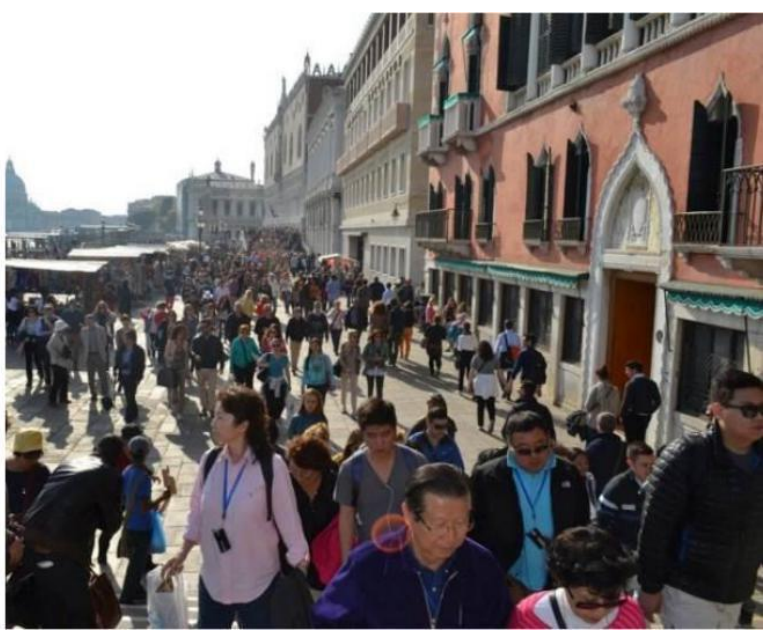

Fonte: Tiago Colle, abril/2014.

Para GEHL (2013), ao se valorizar e priorizar a escala humana nos espaços públicos da cidade, as conexões humanas são favorecidas e se retoma a arte do encontro das pessoas. Isso cria uma relação muito mais agradável e proveitosa entre cidade e seus habitantes.

“(..) As cidades devem pressionar os urbanistas e os arquitetos a reforçarem as áreas de pedestres como uma política urbana integrada para desenvolver cidades vivas, seguras, sustentáveis e saudáveis. Igualmente urgente é reforçar a função social do espaço da cidade como local de encontro que contribui para os objetivos da sustentabilidade social e para uma sociedade democrática e aberta." (Gehl, Jan. Cidade para Pessoas, p. 6, 2013.). 


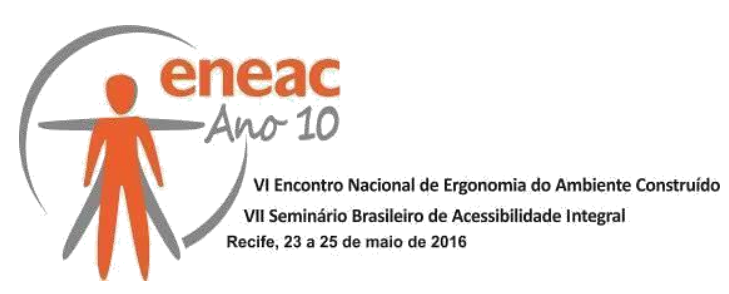

Com o objetivo de resolver os conflitos entre pedestres e automóveis pode-se citar os exemplos de intervenções realizadas nas cidades de Copenhague e Curitiba que limitaram as áreas para os carros e priorizaram os pedestres, promovendo assim a humanização dessas áreas de intervenção. As figuras 4 e 5 mostram ruas das duas cidades citadas, onde estão marcadas as linhas de visão dos pedestres, a priorização desta escala e a conseqüente humanização das vias.

Figura 4. Copenhague - Stroget, Rua para Pedestres e preocupação com a escala Humana

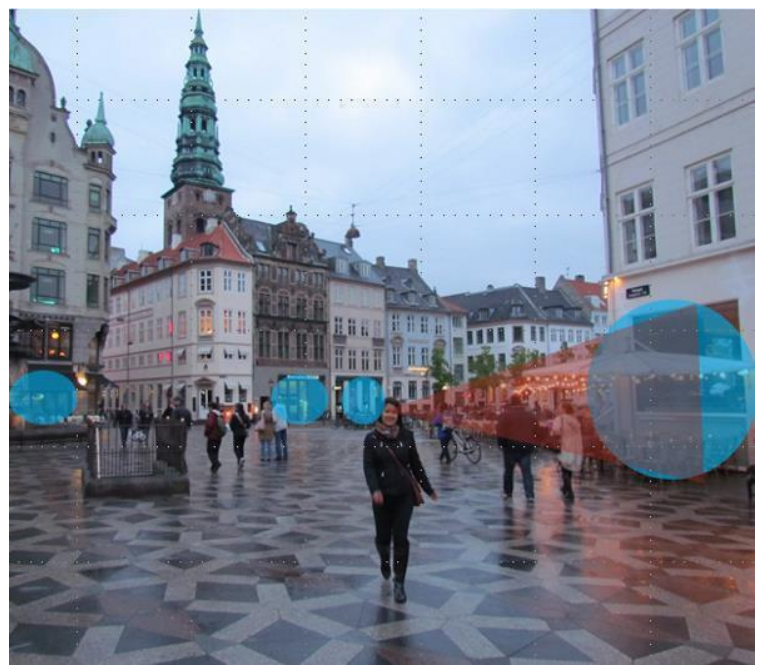

Fonte: http://ruadegente.blogspot.com.br, acessado em 27/03/2015.
Figura 5. Curitiba - Rua das Flores. Rua para pedestres e Relação direta das edificações com os pedestres

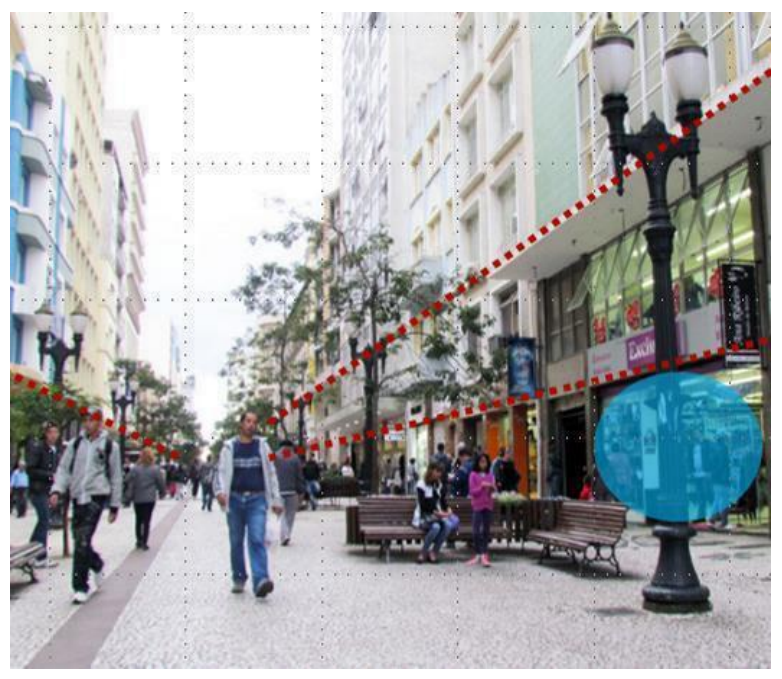

Fonte: http://fperisse.blogspot.com.br/, acessado em 05/03/2015.

Na década de 60, Jacobs (2001) já ressaltava o caráter de segurança pública das calçadas e afirmava que uma rua movimentada consegue garantir a segurança enquanto que uma rua deserta, não. Numa cidade onde os passeios públicos não são valorizados e por isso as pessoas não são estimuladas a utilizá-los, as ruas se tornam cada vez mais inseguras. (JACOBS, 2001)

A humanização da cidade depende da promoção do encontro de pessoas com pessoas e delas com a cidade. Sem a relação dos edifícios, das quadras e principalmente dos espaços públicos (principalmente as calçadas) com seus habitantes, as cidades continuarão sem vida, monótonas (GEHL, 2013).

Jan Gehl (2013), listou 12 critérios de qualidade com respeito à paisagem do pedestre, conforme figura 6 . Ele cita que os melhores e mais funcionais espaços urbanos do mundo demonstram um cuidadoso tratamento geral de todos os fatores mencionados. 


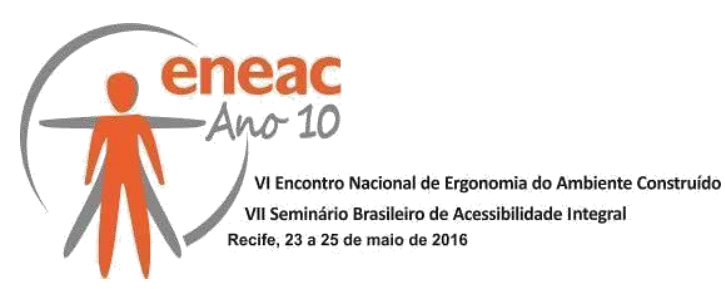

Figura 6. Os 12 critérios de qualidade para os espaços públicos, por Jan Gehl.

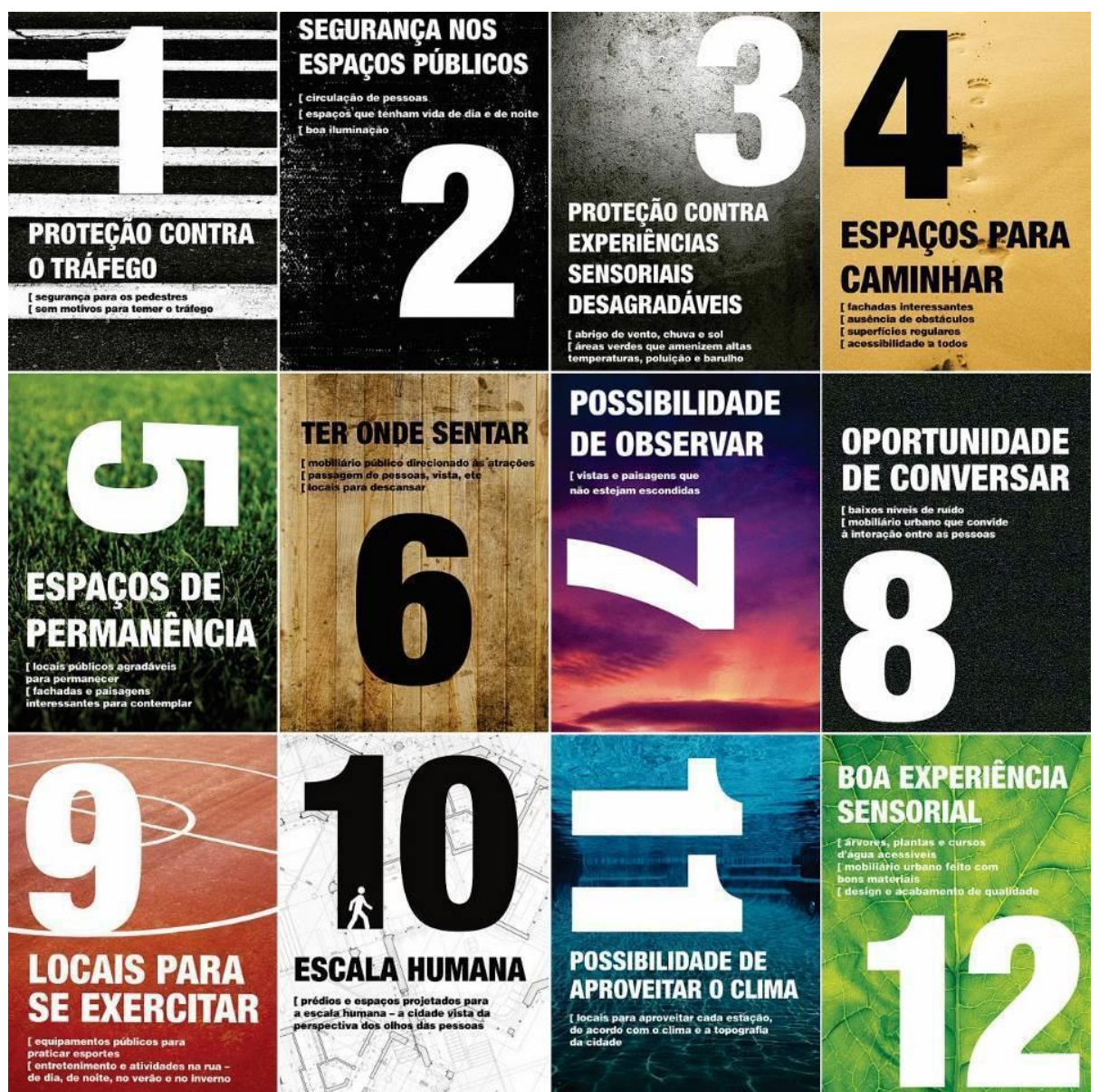

Fonte: www.cidadesparapessoas.com/2012/06/07/12-criterios-para-determinar-um-bom-espacopublico. Acessado em 20/março/2014.

\section{OBJETIVOS}

\subsection{Objetivos Geral e Específicos}

O objetivo geral dessa pesquisa é analisar espacialmente uma fatia do tecido urbano do Centro Histórico Comercial do Recife, situado nos bairros de São José e de Santo Antônio, para propor diretrizes de Requalificação Urbana com o intuito de amenizar os problemas ambientais e promover acessibilidade adequada.

Como Objetivos Específicos temos:

Analisar e compreender a conformação físico-espacial da área;

Propor diretrizes para inserção de espaços de convivência através da utilização de mobiliário urbano, revestimentos adequados e vegetação, promovendo mais identidade, socialização e conforto aos usuários;

Propor diretrizes de melhoria dos espaços públicos, como calçadas e vias, visando melhorar a utilização destes espaços pelas pessoas. 


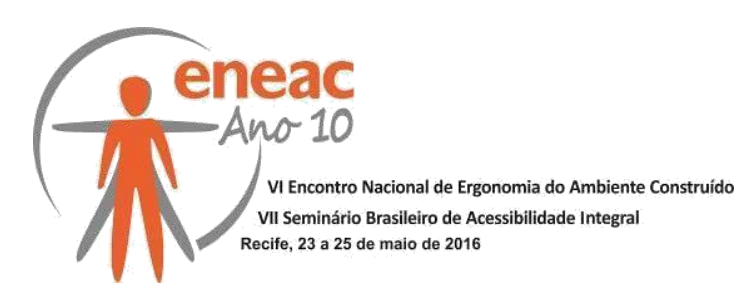

\section{METODOLOGIA}

\subsection{O Lugar}

A área de estudo escolhida encontra-se localizada no Bairro de São José e em parte do Bairro de Santo Antônio, na Cidade do Recife/PE. Está delimitada pelas vias: ao norte, Avenida Nossa Senhora do Carmo; a oeste, Avenida Dantas Barreto; ao sul, Rua São João; e a leste, Cais de Santa Rita.

Segundo a Lei № 16.293, de 22/01/97, os bairros de São José e Santo Antônio, onde está inserida a área de estudo, encontram-se inseridos na Região Político-Administrativa 01, na microrregião 1.2 e possui limites com os bairros: Recife, Cabanga, Coelhos, Afogados.

Para a Lei № 16.176/96 (Lei de Uso e Ocupação do Solo da Cidade do Recife) e o Plano Diretor Recife, grande parte da área dos bairros de São José e Santo Antônio estão incluídas na Zona Especial de Preservação Histórico (ZEPH), ZEPH 10. As ZEPHs são formadas por sítios, ruínas, conjuntos ou edifícios isolados de expressão artística, cultural, histórica, arqueológica ou paisagística, considerados representativos da memória arquitetônica, paisagística e urbanística da cidade (LEI DE USO E OCUPAÇÃO DO SOLO DA CIDADE DO RECIFE, art.14). A ZEPH 10 abriga o maior número de edificações de valor e de monumentos significativos na cidade, não possui legislação específica como as ZEPHs 08 e 09, apesar de prevista no Plano Diretor do Recife. As ZEPHs se dividem em dois setores, o Setor de Proteção Rigorosa (SPR), cujos critérios de intervenção no patrimônio são mais rígidos e visam a manutenção das características do lugar, e o Setor de Proteção Ambiental (SPA), que funciona como território de transição entre as SPRs e as demais áreas adjacentes de seu entorno. Nas Zonas Especiais de Preservação do Patrimônio HistóricoCultural - ZEPH, os requisitos de estacionamento serão objeto de análise especial pelo órgão competente do Município (LEI DE USO E OCUPAÇÃO DO SOLO DA CIDADE DO RECIFE, art.40). Ainda de acordo com a Lei 16.176/96 e Plano Diretor do Recife (2008), nos bairros mencionados encontram-se áreas situadas na Zona Especial de Dinamização Econômica (ZEDE) de Centro Principal (CP), que são as áreas, potenciais ou consolidadas, que concentram atividades múltiplas e que tem um raio de influência regional e metropolitano (PLANO DIRETOR DO RECIFE, art.132).

No Bairro de São José, boa parte de sua área encontra-se também subordinada às diretrizes da Zona de Ambiente Construído (ZAC) moderada, caracterizada por ocupação diversificada e facilidade de acessos, objetivando moderar a ocupação, com potencialidade para novos padrões de adensamento, observando-se a capacidade das infraestruturas locais (PLANO DIRETOR DO RECIFE, art.96).

\subsection{Procedimentos}

Após a delimitação da área de estudo, seguiu-se com a construção do referencial teórico sobre temas como requalificação urbana, mobilidade urbana, espaços públicos, pedestrianização, escala humana das cidades, a partir dos tetos de autores como Jan Gehl (2013), Jane Jacobs (2013), Gordon Cullen (2015) e Kevin Lynch (1999).

Foram realizados levantamentos fotográficos e físicos através de visitas a campo em dias e horários diferentes para observar e documentar as diferentes formas de utilização da área, além dos aspectos físicos (calçadas, edificações, mobiliário urbano, entre outros).

Como complemento da análise, foram elaborados questionários para entrevistas com usuários, proprietários de estabelecimentos e moradores da área, através de perguntas norteadoras que focaram na imagem e na relação das pessoas com a área. Os entrevistados foram escolhidos de forma aleatória, assim como em dia e horários distintos, 


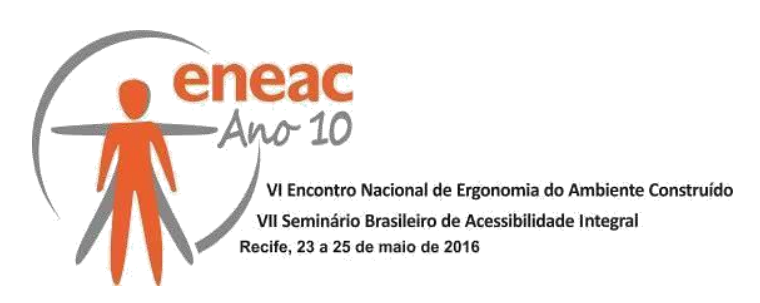

para que o resultado obtido fosse o mais próximo possível da realidade, demonstrando como a população que utiliza esses espaços os vê e os sente. Três tipos de questionários foram elaborados: tipo I (questões de múltipla escolha aplicadas a 30 pessoas) baseado no sistema NEWS (Neighborhooh Enviromental Walkability Scale) (Saelens et al, 2003); tipo II (questões abertas/discursivas, aplicadas a 6 pessoas), onde o entrevistado era solicitado a descrever o lugar, listar pontos positivos e negativos e o que gostaria que melhorasse; e tipo III (mapa mental, elaborado por 5 pessoas) é uma solicitação de desenho/descrição da área pelo entrevistado, baseado no método de pesquisa realizado por Kevin Lynch (1999) constante no livro A Imagem da Cidade.

Após as etapas de levantamentos de dados e análises, foram indicadas diretrizes projetuais norteadoras de uma futura intervenção urbana na área de estudo.

\subsection{Estudos de Caso}

Foram estudados dois projetos de requalificação urbana: Pike-Pine, em Seatle - EUA e State Street, em Wisconsin - EUA, como embasamento para a definição das diretrizes propostas.

Os dois projetos estão localizados em áreas históricas que passaram por processo de degradação, abandono e subutilização de seus espaços.

O projeto de Reforma Urbana do Corredor Pike-Pine, se baseia em três camadas: a camada mais superficial, light layer, onde se deve estimular a vida nas ruas através de vários eventos e oficinas oferecidos. A segunda camada, middle layer, é a parte do projeto onde se preveem as pavimentações, dimensões e mobiliários para as vias e calçadas. E a última camada, deep layer, se relaciona ao incentivo da intermodalidade dos deslocamentos na área. Nesse estudo de caso, é interessante a preocupação em explicitar o tipo de intervenção em cada área e de acordo com os níveis.

O projeto de requalificação para a State Street se baseia em quatro princípios: flexibilidade, sobreposição de usos num mesmo espaço; atemporalidade, utilização de equipamentos urbanos que não se relacionem com uma época específica; sustentabilidade, emprego de técnicas e materiais que sejam menos agressivos ao meio ambiente; $e$ manutenção/durabilidade, utilização de materiais que resistam bem às intempéries e que necessitem de pouca manutenção.

\subsection{Questionários e Entrevistas}

As entrevistas com os usuários do local foram realizadas nos dias 24,27 e 29 de outubro de 2015. Foram aplicados três tipos de questionários, o tipo I, com questões fechadas e respostas afirmativas e negativas, o tipo II, com questões abertas (entrevistas), onde os usuários tiveram maior liberdade de expor opiniões e sugestões de melhorias, e o tipo III, que propunha aos usuários desenhar suas impressões da área, formalizando mapas metais e cognitivos da área.

\section{ANÁLISE E RESULTADOS}

O diagnóstico desenvolvido através de levantamentos fotográficos e físicos e de análises dos resultados obtidos a partir da aplicação de questionários aos usuários, questionários estes com perguntas que foram embasadas nos conceitos de Kevin Lynch (1999). 


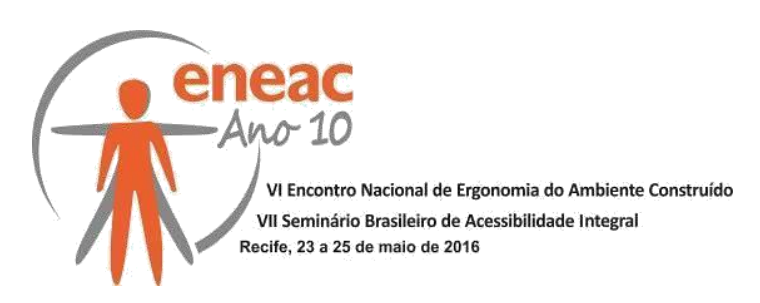

Os seguintes aspectos foram destacados no diagnóstico: físicos (vias, calçadas), econômicos (usos), ambientais (arborização, sombreamento e microclima) e sociais (imagem do lugar, percepção do usuário).

\subsection{Acessibilidade, Mobilidade e Conectividade}

Segundo LYNCH (1999), as vias são um dos elementos da imagem urbana que podem se referir a formas físicas. Para ele as vias são os canais ao longo dos quais o observador se move, usual, ocasional ou potencialmente. As pessoas observam a cidade à medida que nelas se deslocam e os outros elementos organizam-se e relacionam-se ao longo destas vias. Como na área estudada, as ruas são bastante parecidas quanto às tipologias das suas edificações, às larguras das faixas de circulação de carros, larguras de calçadas e aos usos, os pátios das igrejas se destacam por serem espaços mais amplos.

Dentro do conceito de vias de LYNCH (1999) também se incluem as calçadas, pois é através delas que os pedestres (observadores) deveriam se deslocar.

Com a aplicação dos questionários e das entrevistas, foi possível verificar alguns pontos relacionados à acessibilidade, a mobilidade e a conectividade:

\section{Questionários:}

O deslocamento dos usuários até a área é realizado em proporções iguais entre carros e transporte público, $46 \%$ e $47 \%$ respectivamente, restando apenas $7 \%$ dos deslocamentos por meio de bicicletas.

$87 \%$ dos entrevistados afirmaram ser difícil estacionar na área, $6 \%$ que não é difícil e $7 \%$ que as vezes é difícil.

Apesar de $57 \%$ observarem que a maioria das ruas apresentarem calçadas, $93 \%$ afirmam ser difícil caminhar, por que as calçadas são estreitas, $100 \%$ destacam que existem muitos obstáculos nos percursos, 93\% afirmam que as calçadas são mal cuidadas e $87 \%$ identificam os ambulantes como responsáveis por obstruírem suas calçadas.

Entrevistas:

Os usuários sinalizaram o mobiliário urbano mal posicionado (postes, lixeiras, placas de sinalização, etc.);

Citaram a dificuldade de circulação nas calçadas devido à presença de ambulantes; aos desníveis, à pavimentação quebrada; à infraestrutura mal posicionada (caixas de inspeção de concessionárias de energia, telefonia, água e esgoto) e ao dimensionamento inadequado.

\subsection{Imagem do Lugar}

A caracterização da imagem do lugar foi possível, principalmente através dos mapas mentais construídos pelos usuários. Esse método foi utilizado por Lynch (1999) na década de 1960, ao analisar as cidades norte-americanas de Boston, Jersey City e Los Angeles. As figuras 7 e 8 ilustram dois mapas mentais produzidos por usuários da área de estudo. 


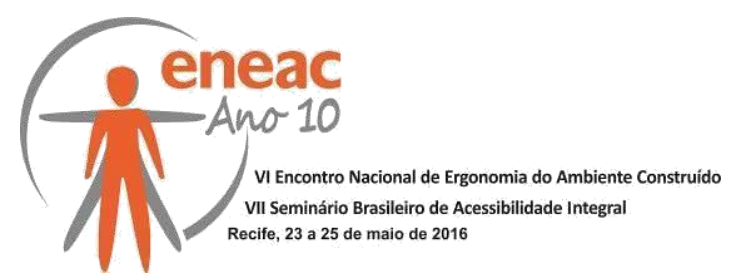

Figura 7. Mapa mental desenhando por Rafaella, 35 anos.

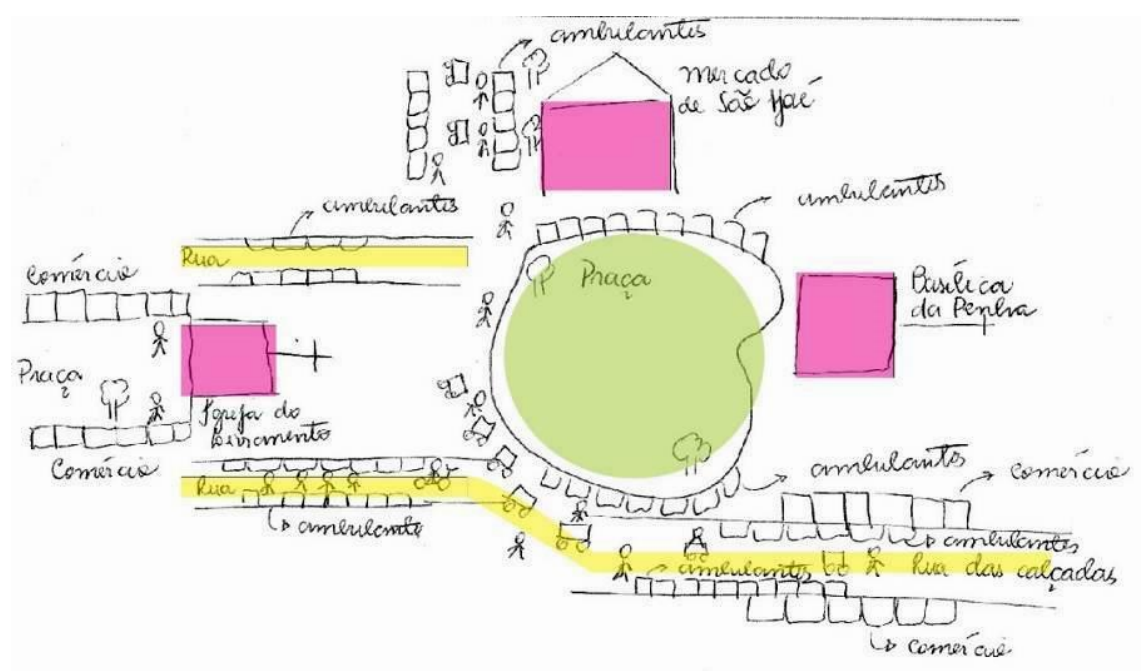

Realizado em outubro/2015.

Figura 8. Mapa mental desenhando por Marly, 58 anos.

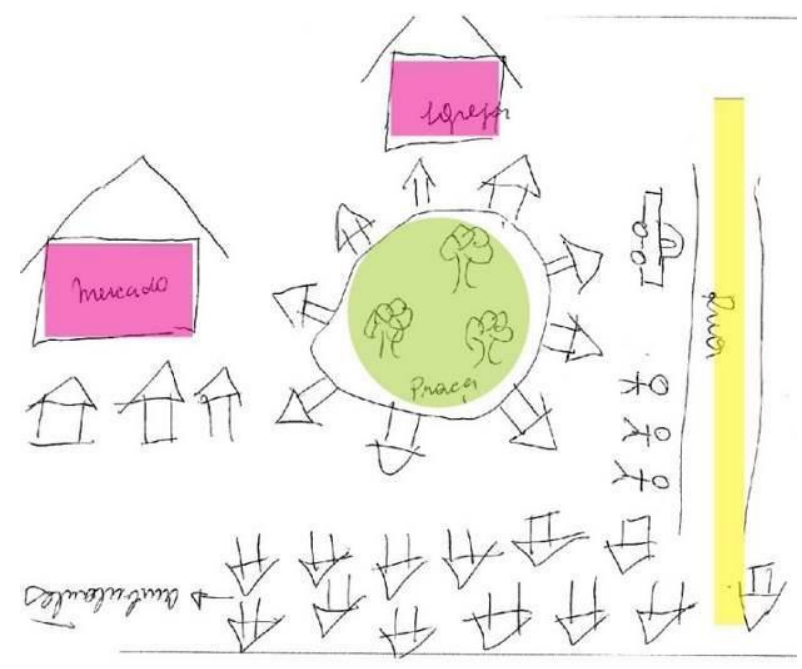

Realizado em outubro/2015.

É possível afirmar, com a análise dos mapas mentais, que a imagem do lugar é positiva e identificar claramente a importância dos vazios urbanos existentes (pátios e praças) para a conformação dessa imagem. A praça é colocada como elemento central, definidor da posição dos demais elementos. Além disso, há a sinalização da presença de edifícios simbólicos como a igreja e o mercado e da sua hierarquia em relação às demais tipologias arquitetônicas. Também é possível perceber que nos mapas foi dado mais destaque às pessoas e à vegetação do que aos automóveis. 


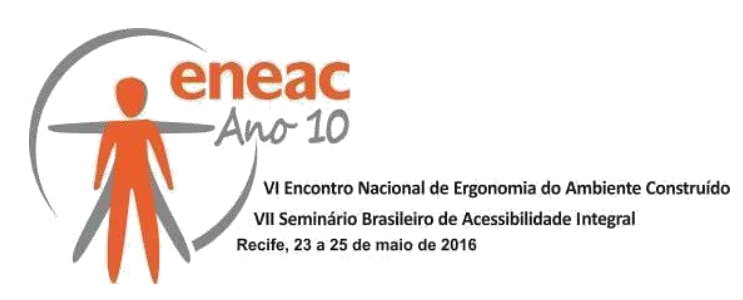

\subsection{Nível de Satisfação com o Lugar}

Apesar de ter sido identificada uma imagem positiva do lugar, nos questionários e nas entrevistas, os usuários da área rapidamente identificavam os problemas enquanto sentiam mais dificuldade em sinalizar as potencialidades. Quando solicitados a descrever as melhorias que gostariam de ver na área, foram elencadas as seguintes: restringir acesso de veículos, incentivar o uso de bicicletas, eliminar estacionamentos nas ruas, conservação e reforma nos prédios históricos, mais árvores, segurança, acessibilidade, iluminação adequada, organização do comércio, ruas limpas e calçadas para caminhar.

\subsection{Diretrizes Projetuais}

Para traçar diretrizes projetuais para a área de estudo foi feita a compilação das impressões apresentadas nos três instrumentos de pesquisa e da analise dos estudos de caso semelhantes. A seguir serão apresentadas as diretrizes projetuais propostas em dois eixos de intervenção.

\begin{tabular}{|c|c|c|}
\hline Eixo de intervenção & Fraquezas e Ameaças & Diretrizes \\
\hline $\begin{array}{l}\text { Mobilidade Urbana } \\
\text { Sustentável }\end{array}$ & $\begin{array}{l}\text { Falta de Acessibilidade; } \\
\text { Falta de incentivo a } \\
\text { outros modais de } \\
\text { deslocamento; } \\
\text { Calçadas estreitas e } \\
\text { degradadas. }\end{array}$ & $\begin{array}{l}\text { Incentivar o uso de diferentes modais de } \\
\text { deslocamento de/para área de estudo, com } \\
\text { criação de ciclofaixas/ciclovias, estação com } \\
\text { paraciclos, ruas pedestrianizadas; } \\
\text { Setorizar áreas para estacionamento que não } \\
\text { interfiram no fluxo de pedestres; } \\
\text { Melhorar as conexões existentes entre as vias } \\
\text { locais e as edificações históricas, através da } \\
\text { pedestrianização das ruas e diminuição da } \\
\text { interferência entre os diferentes fluxos de } \\
\text { deslocamentos; } \\
\text { Adequar calçadas e ruas às condições de } \\
\text { acessibilidade de acordo com as normas de } \\
\text { acessibilidade vigentes e desenho universal } \\
\text { (ABNT NBR 9050). }\end{array}$ \\
\hline $\begin{array}{l}\text { Requalificação } \\
\text { Urbana }\end{array}$ & $\begin{array}{l}\text { Falta de arborização e } \\
\text { áreas verdes; } \\
\text { Falta de segurança } \\
\text { pública; } \\
\text { Desordenamento do } \\
\text { comércio informal; } \\
\text { Limpeza urbana } \\
\text { ineficiente; } \\
\text { Uso estritamente } \\
\text { comercial } \\
\text { Falta de Planejamento e } \\
\text { Gestão Pública; }\end{array}$ & $\begin{array}{l}\text { Melhorar a qualidade do ambiente com o plantio } \\
\text { de vegetação e iluminação adequada, propor } \\
\text { melhoria e ordenamento do mobiliário urbano } \\
\text { (postes, orelhões, placas de sinalização, } \\
\text { bancos, lixeiras), criar mais espaços de } \\
\text { convivência e requalificar praças, pátios e largos } \\
\text { existentes; } \\
\text { Trazer atrativos para humanizar as ruas, } \\
\text { incentivando atividades culturais temporárias } \\
\text { nos espaços de convivência; } \\
\text { Ordenar o comércio informal na área, } \\
\text { realocando-o para a Avenida Dantas Barreto e } \\
\text { para o anexo do Mercado de São José, } \\
\text { propondo locais específicos na área onde seja } \\
\text { possível a utilização de barracas e carrinhos } \\
\text { Criar projeto de gestão de limpeza urbana }\end{array}$ \\
\hline
\end{tabular}




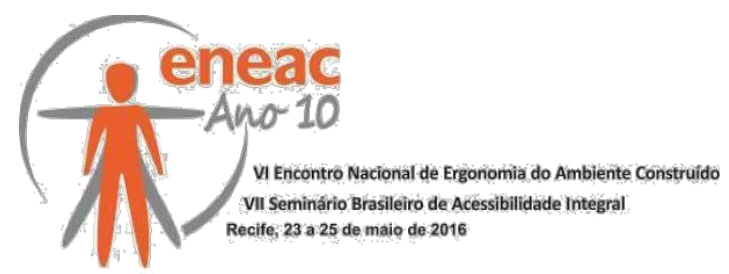

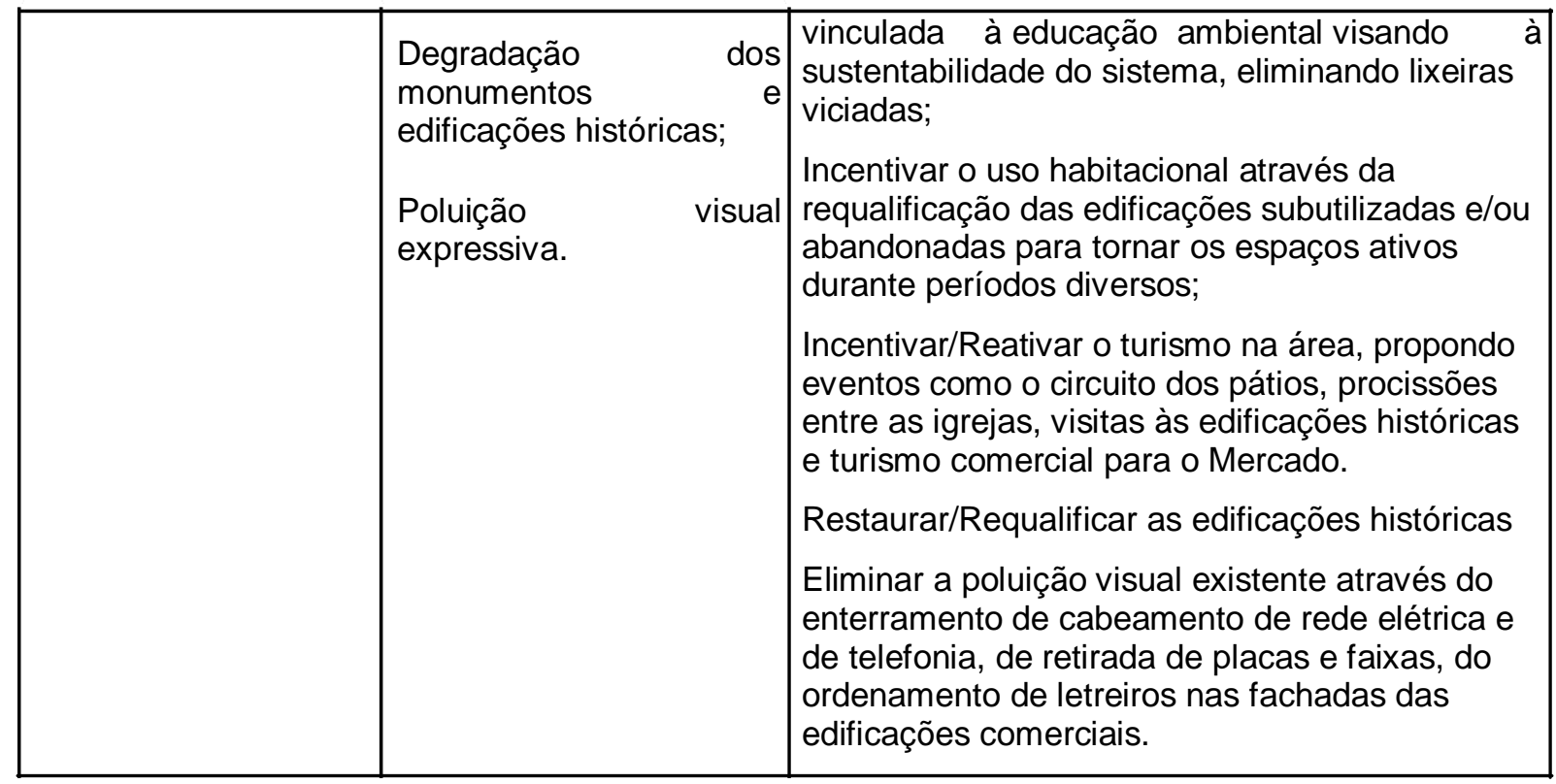

Figura 9. Exemplificação de algumas diretrizes propostas. Rua das Calçadas, Praça Dom Vital e Mercado de São José.

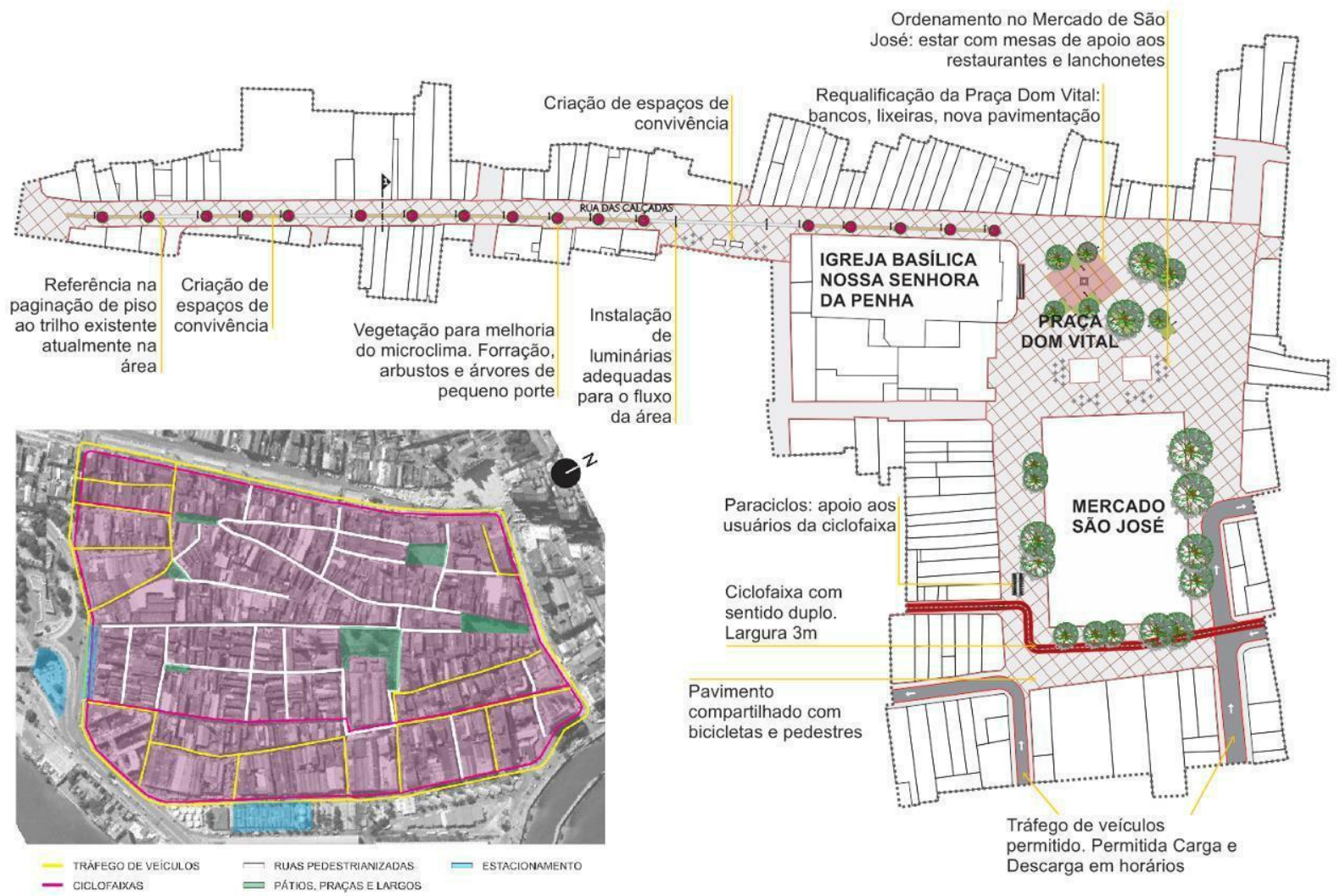




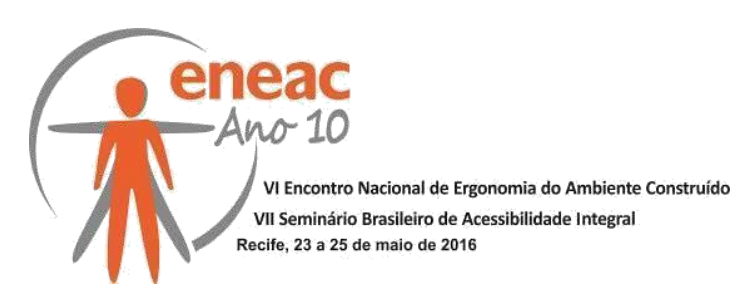

\section{CONSIDERAÇÕES FINAIS}

Novas pesquisas devem ser realizadas com base nos princípios de cidades compactas e sustentáveis como forma de complementar e aprofundar os problemas identificados. $\mathrm{O}$ diagnóstico deve ser aprofundado através de levantamentos topográficos, medições relacionadas ao conforto ambiental, cadastros físicos e legais das edificações, levantamento do estado de conservação real das edificações, estudos de fachadas com cores e letreiros.

\section{REFERÊNCIAS BIBLIOGRÁFICAS}

Associação Brasileira de Normas Técnicas NBR 9050: 1994. Acessibilidade de pessoas portadoras de deficiências a edificação, espaço mobiliário e equipamentos urbanos / Associação Brasileira de Normas Técnicas. Rio de janeiro: ABNT, 1994.

BORGES, Leandro. Como desenvolver uma matriz ou análise SWOT (FOFA). Disponível em: http://blog.luz.vc/o-que-e/como-desenvolver-uma-matriz-ou-analise-swot-fofa/. Acesso em 01/09/2015.

CULLEN, Gordon. Paisagem Urbana. Lisboa: Edições 70, 2015.

GEHL, Jan. Cidade para Pessoas. São Paulo: Perspectiva, 2013.

JACOBS, Jane. Morte e Vida de Grandes Cidades. São Paulo: Martins Fontes, 2013.

LYNCH, Kevin. A Imagem da Cidade. São Paulo: Martins Fontes, 1999.

MENEZES, José Luiz Mota. Atlas histórico-cartográfico do Recife. Recife: FUNDAJ/Editora Massangana, 1988.

Ministério das Cidades. Política de Mobilidade Urbana Sustentável: Cadernos MCidades Mobilidade Urbana no 6. Brasília, 2004.

NEVES, A. L.; MENDONÇA JÚNIOR, J. L. Os edifícios religiosos e a estrutura urbana dos bairros de Santo Antônio e São José - 1654-1800. Humanae, v.1, n.1, p.1-13, Set 2007.

RECIFE, Lei Municipal no 16.176, de 09 de abril de 1996. Estabelece a Lei de Uso e Ocupação do Solo da Cidade do Recife.

Lei Municipal no 16.293, de 22 de janeiro de 1997. Dispõe sobre as Regiões Político Administrativas do municipio do recife e dá outras providências.

Lei Municipal no 16.293, de 19 de dezembro de 1991. Estabelece as Diretrizes Gerais em Matéria de Política Urbana, institui o Plano Diretor de desenvolvimento da cidade do Recife, cria o Sistema de Planejamento e de Informações da cidade e dá outras providências.

SAELENS, B. E.; SALLIS, J. F.; FRANK, L. D. Environmental correlates of walking and cycling: findings from the transportation, urban design, and planning literatures. Annals of behavioral medicine : a publication of the Society of Behavioral Medicine, v. 25, n. 2, p. 80-91, 2003. 